\title{
Vulnerability to Landslides in the City of Sao Paulo
}

\author{
Letícia Palazzi Perez ${ }^{1,2}$ and Jose Rodolfo Scarati Martins ${ }^{2}$ \\ 1. Faculty of Humanities, University of Sao Paulo, Sao Paulo 01402000, Brazil \\ 2. School of Engineering, University of Sao Paulo, Sao Paulo 05508010, Brazil
}

\begin{abstract}
The City of São Paulo is the largest urban occupation in Brazil, covering 1,500 km². Its population is approximately 12 million inhabitants, $12 \%$ of them living in subnormal agglomerates, the IBGE (Brazilian Agency for Statistics and Geography) denomination for informal settlements, mostly located in river floodplain areas or top of hills. The extreme high level of soil sealing and high slopes have a fundamental role to explain the increase the risks of mass movements or landslides, related to precipitation magnitude and duration. This article presents the construction of curves coupling landslides occurrences and precipitation based on the data analysis of different basins in the city of São Paulo, considering also the probability and duration of the rainfall event in order to establish a vulnerability index to estimate the vulnerability category of an specific area. Based on the data analysis of instantaneous radar rain records for seven extreme rainfall events where landslides occurrences records were available, it was possible to plot sigmoid curves linking the number of occurrences with the event probability in terms of return period.
\end{abstract}

Key words: Landslide risk, urban vulnerability, GIS (Geographic Information System).

\section{Introduction}

São Paulo City is the largest urban area in Brazil with almost $80 \%$ of its $1,500 \mathrm{~km}^{2}$ area impervious and approximately 12 million inhabitants [1]. Informal settlements associated with the soil sealing, occupation in high slopes and river floodplain areas, improve landslides problems and flooding due to then inefficiency of storm water systems, directly reflecting in economical losses and even deaths.

Based on the analysis of rainfall data taken from records of seven extreme events in the last 10 years and spatial correlations of landslides occurrences in informal settlements, usually the home for low-income family, this article has the objective to present a method to evaluate the spatial landslide vulnerability as a tool for city resilience improvement.

Assuming that landslides are hydrologically driven events and directly correlated to precipitation, it can be assumed that the risk is a function of the probability of the event, the vulnerability of the area and the associated damage. Thus, the local vulnerability

Correpsonding author: Letícia Palazzi Perez, Ph.D., research fields: GIS, hydrology and urban studies. function becomes an important information for decision makers and stakeholders to assess urban interventions and public policies for land use and occupation.

As a result, vulnerability functions combining rainfall probability and local vulnerability area are presented in the form of maps for 2, 5 and 10 years of return period and their spatial distributions are analyzed in terms of city occupation and growth.

\section{Methodology}

\subsection{Study Area}

Sao Paulo City has a population density of 7,387 inhabitants per $\mathrm{km}^{2}, 12 \%$ of them living in informal settlements [2]. Recent studies indicate that 85\% 90\% of the surface area became artificially impervious by ordinary urban land use due to population growth in the last 50 years [2]. Situated in the upper portion of Tietê River Basin (Fig. 1), the basin was initially divided into 13 sub catchment areas taking into account the significant tributaries.

\subsection{Extreme Events}

Seven extreme rainfall events were selected for 


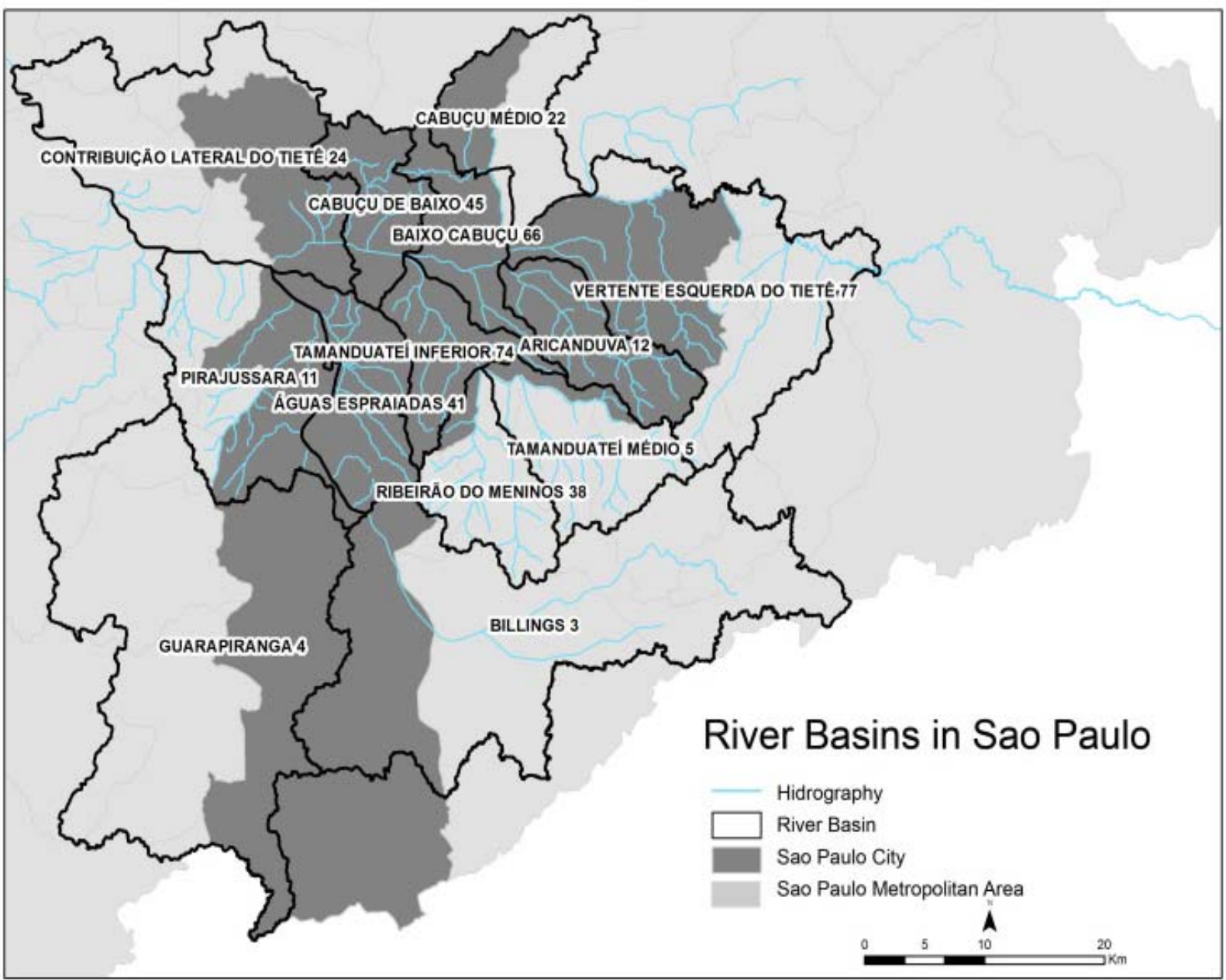

Fig. 1 Sao Paulo City-river basins.

vulnerability analysis, considering data from the meteorological C-band radar correlated with 23 telemetric rain stations that provide adequate time and spatial rainfall distribution in a 10 min time step. The selected events considered different durations and return periods as shown in Table 1 .

The accumulated total rainfall for intervals of 6,12 , 24 and 48 hours were calculated for each event from raster files ASCII-type containing the radar images [3] with the space-intensity distribution, where each pixel represents $2 \times 2 \mathrm{~km} \times 10$ min precipitation (Fig. 2), properly consisted and correlated with ground information provided by telemetric stations [4].

The average precipitation was calculated for each of the 13 sub catchments and selected durations, as well as the landslides occurrences were collected and spatialized for the same intervals. The return periods for each event were established considering Sao Paulo rainfall IDF (intensity-duration-frequency) equation [5]. For each duration, the number of land sliding occurrence presented in Table 2 in each sub catchment was normalized by the total number of occurrences and classified considering 12 precipitation categories [6]. This procedure resulted in specific vulnerability functions that can be fitted to sigmoid curves as shown in Fig. 3. The resulting curves allow to quantify, for different return periods and durations of precipitation, the expected number or land slide occurrences and categorize the vulnerability of an area or catchment [7]. 


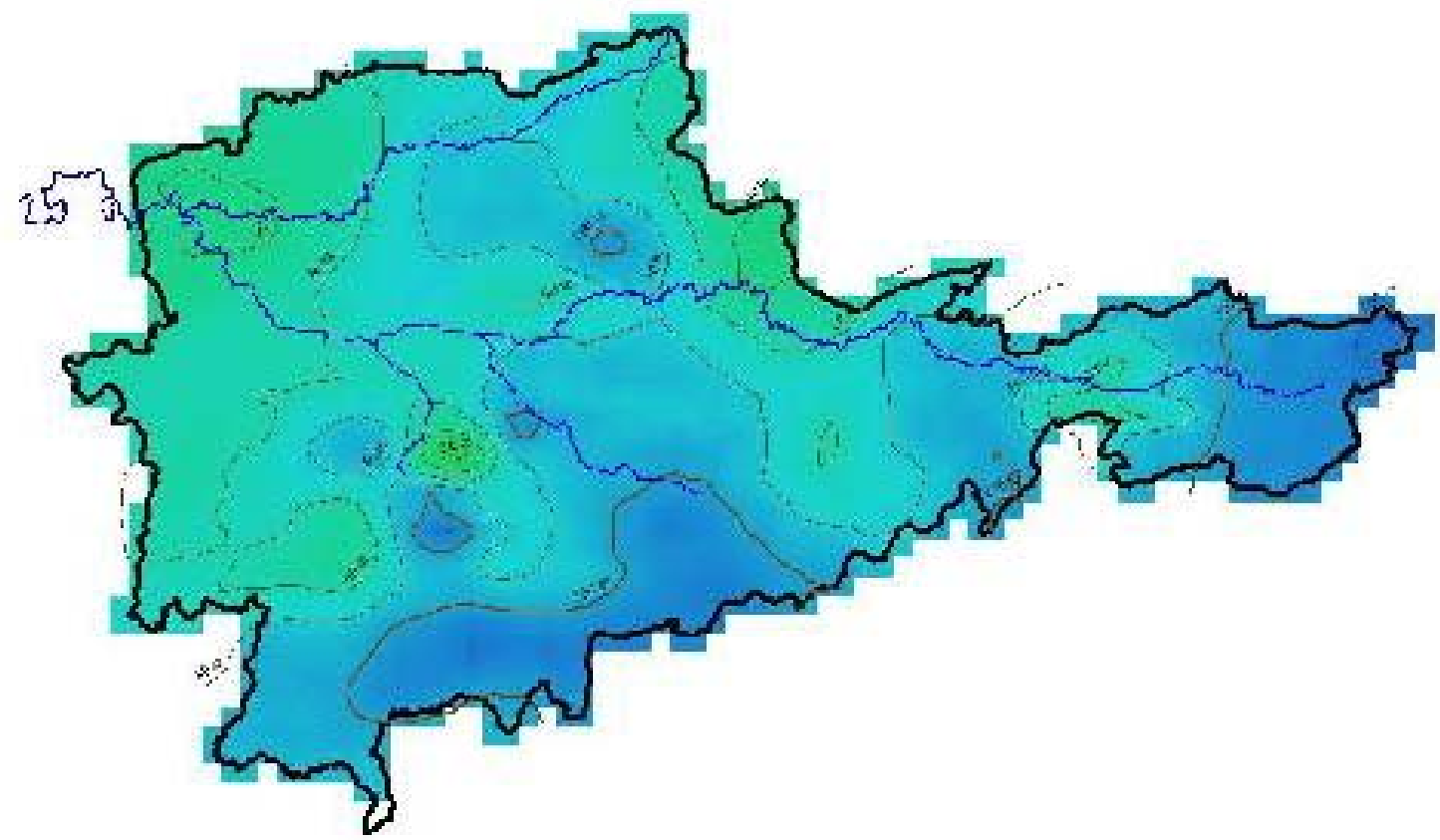

Fig. 2 Accumulated precipitation plot-Dec. 2009.

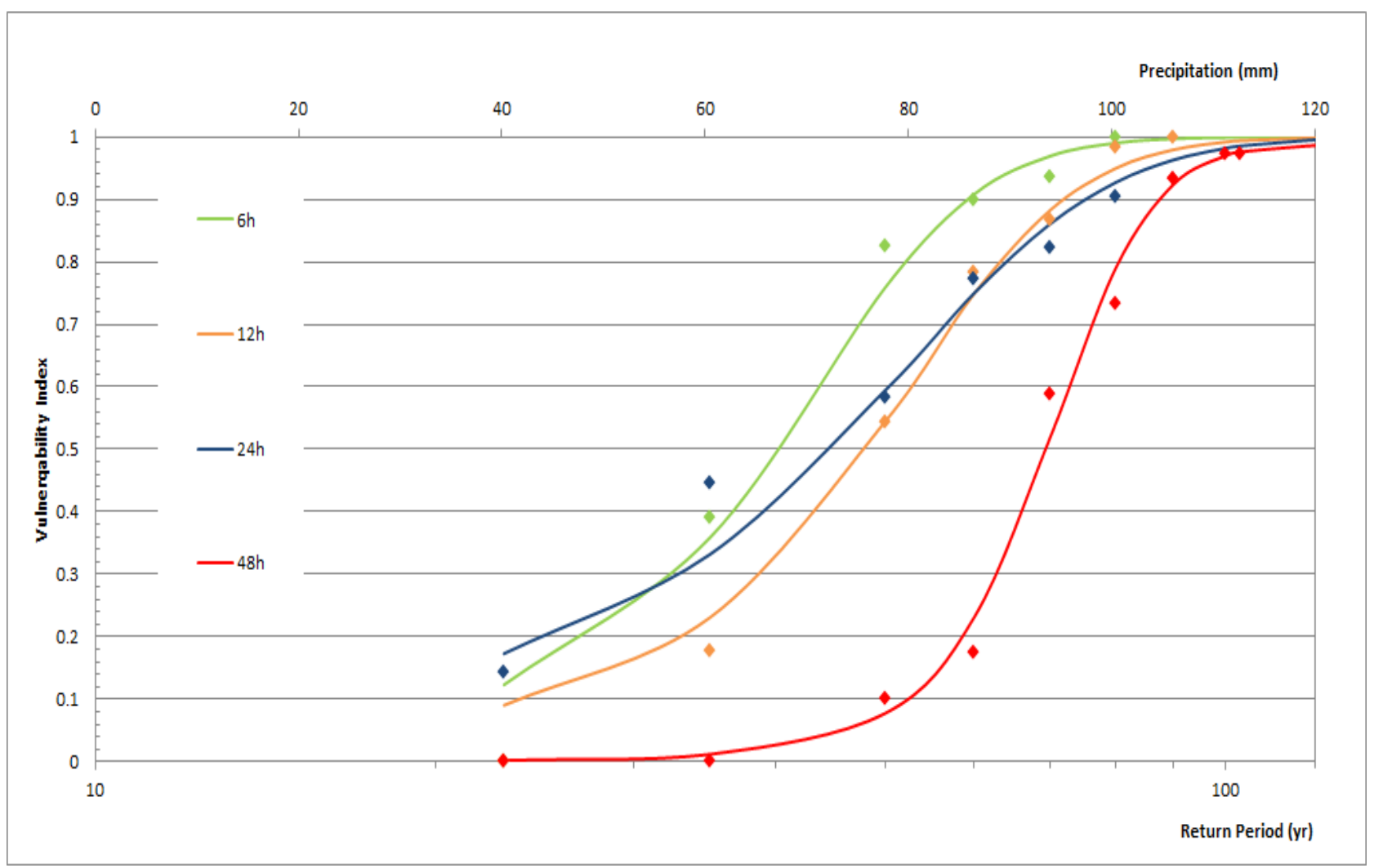

Fig. 3 Vulnerability function to landslide. 

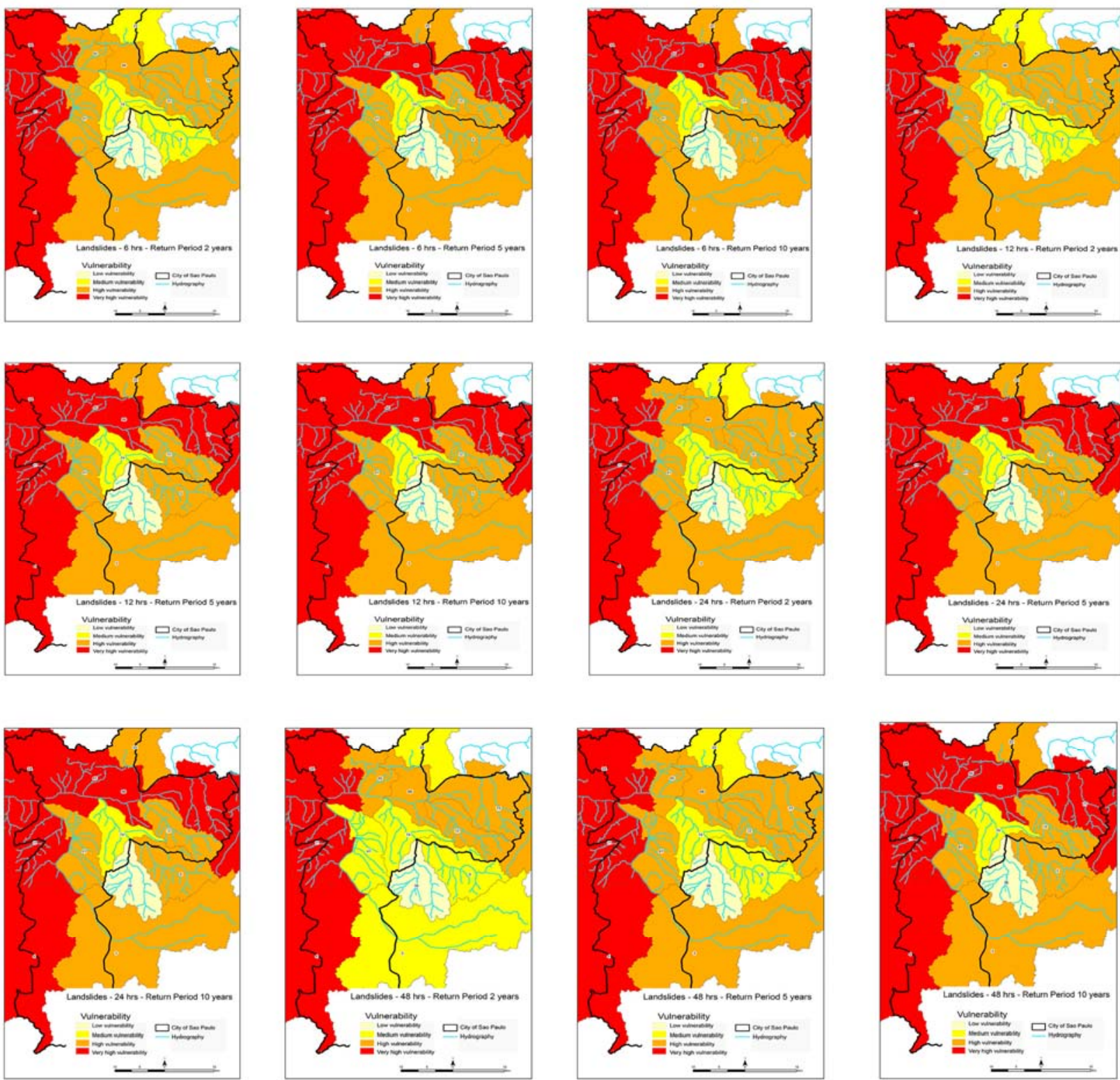

\section{Vulnerability \\ Low vulnerability \\ Medium vulnerability \\ High vulnerability \\ Very high vulnerability}

Fig. 4 Urban vulnerability to landslides for different duration and return period. 


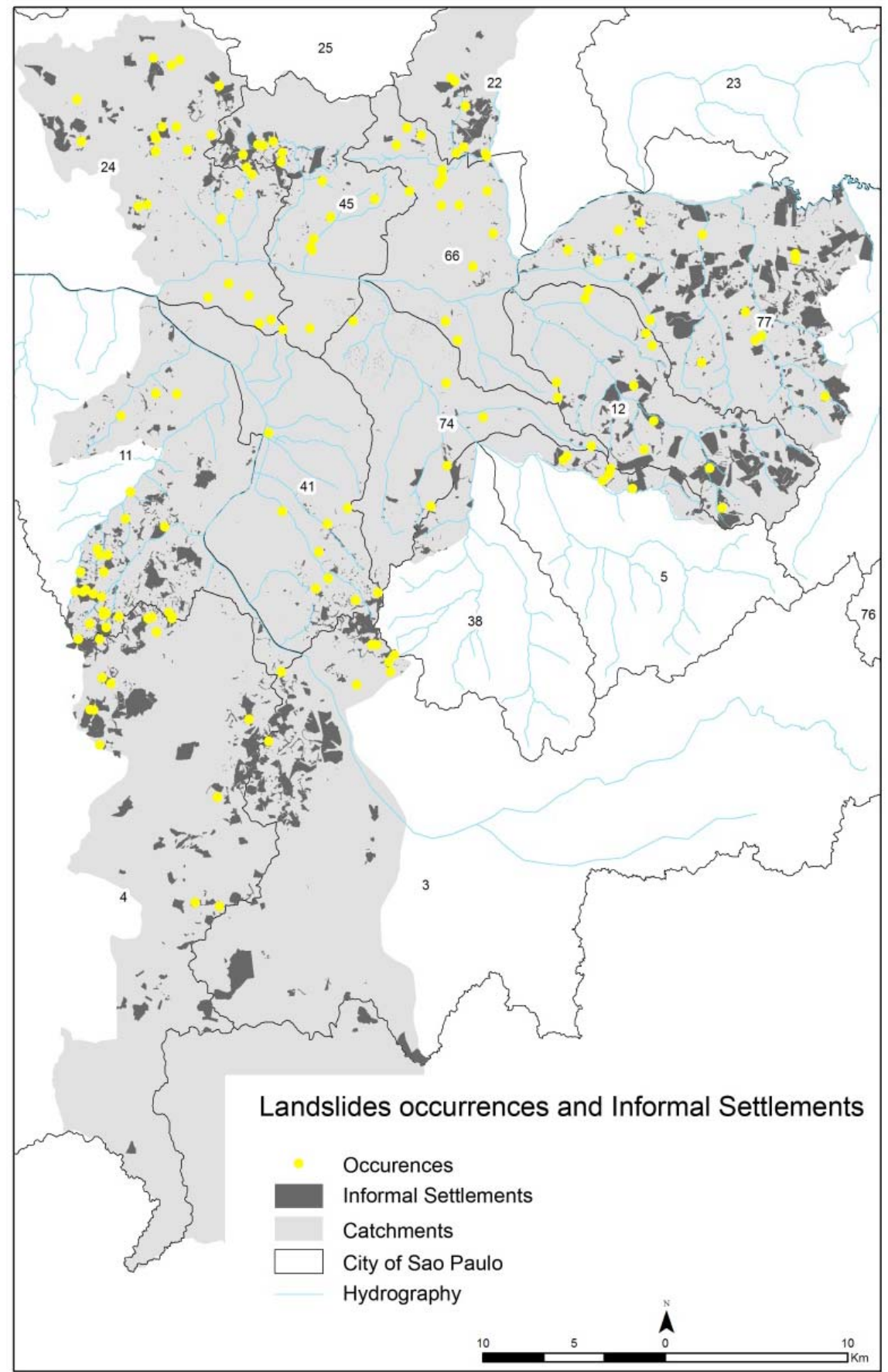

Fig. 5 Spatial division of Sao Paulo City area based on hydrological basins and housing/slums distribution. Source: Refs. [1, 8, 9].

\section{Results and discussion}

The following results were found:

\subsection{Classification of Urban Vulnerability}

Four categories were proposed to parameterize the vulnerability: low vulnerability; medium vulnerability; high vulnerability; and very high vulnerability.

River basins with low vulnerability were considered when number of occurrences for a specific duration and return period was 0 or 1 . The last three categories were proposed in a linear distribution (Table 3). 
Table 1 Selected events for vulnerability analysis.

\begin{tabular}{|c|c|c|c|c|}
\hline Event & Start & End & Duration (h) & Average return period* $(\mathrm{yr})$ \\
\hline May, 2005 & 23/5/05 0:10 & 26/5/05 1:00 & 73 & 7.6 \\
\hline Feb., 2007 & 5/2/07 15:30 & 12/2/07 0:00 & 152 & 18.1 \\
\hline Dec., 2007 & 18/12/07 17:10 & 21/12/07 1:00 & 56 & 2.2 \\
\hline Sep., 2009 & 6/9/09 6:10 & 10/9/09 14:50 & 105 & 14.4 \\
\hline Dec., 2009 & 7/12/09 10:10 & 9/12/09 4:00 & 42 & 3.8 \\
\hline Jan., 2010 & 20/1/10 18:10 & $22 / 1 / 1018: 00$ & 48 & 7.4 \\
\hline Jan., 2011 & 10/1/11 18:10 & 12/1/11 18:00 & 48 & 58.7 \\
\hline
\end{tabular}

*Computed over 6-hour most intensive interval.

Table 2 Vulnerability table.

\begin{tabular}{|c|c|c|c|c|c|c|c|c|c|c|c|c|c|c|}
\hline \multirow[b]{2}{*}{ Name } & \multirow[b]{2}{*}{ ID } & \multirow[b]{2}{*}{ Occurrences } & \multicolumn{3}{|c|}{$6 \mathrm{hrs}$} & \multicolumn{3}{|c|}{$12 \mathrm{hrs}$} & \multicolumn{3}{|c|}{$24 \mathrm{hrs}$} & \multicolumn{3}{|c|}{$48 \mathrm{hrs}$} \\
\hline & & & YR 2 & YR 5 & YR 10 & YR 2 & YR 5 & YR 10 & YR 2 & YR 5 & YR 10 & YR 2 & YR 5 & YR 10 \\
\hline RIBEIRAO DO MENINOS & 38 & 1 & 0.84 & 0.97 & 0.99 & 0.78 & 0.94 & 0.98 & 0.8 & 0.96 & 0.98 & 0.64 & 0.83 & 0.96 \\
\hline TAMANDUATEI INFERIOR & 74 & 5 & 4.2 & 4.85 & 4.95 & 3.9 & 4.7 & 4.9 & 4 & 4.8 & 4.9 & 3.2 & 4.15 & 4.8 \\
\hline TAMANDUATE MEDIO & 5 & 7 & 5.88 & 6.79 & 6.93 & 5.46 & 6.58 & 6.86 & 5.6 & 6.72 & 6.86 & 4.48 & 5.81 & 6.72 \\
\hline CABUCU MEDIO & 22 & 7 & 5.88 & 6.79 & 6.93 & 5.46 & 6.58 & 6.86 & 5.6 & 6.72 & 6.86 & 4.48 & 5.81 & 6.72 \\
\hline BILLINGS & 3 & 8 & 6.72 & 7.76 & 7.92 & 6.24 & 7.52 & 7.84 & 6.4 & 7.68 & 7.84 & 5.12 & 6.64 & 7.68 \\
\hline AGUAS ESPRAIADAS & 41 & 9 & 7.56 & 8.73 & 8.91 & 7.02 & 8.46 & 8.82 & 7.2 & 8.64 & 8.82 & 5.76 & 7.47 & 8.64 \\
\hline ARICANDUVA & 12 & 10 & 8.4 & 9.7 & 9.9 & 7.8 & 9.4 & 9.8 & 8 & 9.6 & 9.8 & 6.4 & 8.3 & 9.6 \\
\hline CABUCU DE BAIXO & 45 & 14 & 11.76 & 13.58 & 13.86 & 10.92 & 13.16 & 13.72 & 11.2 & 13.44 & 13.72 & 8.96 & 11.62 & 13.44 \\
\hline BAIXO CABUCU & 66 & 14 & 11.76 & 13.58 & 13.86 & 10.92 & 13.16 & 13.72 & 11.2 & 13.44 & 13.72 & 8.96 & 11.62 & 13.44 \\
\hline VERTENTE ESQUERDA TIETE & 77 & 14 & 11.76 & 13.58 & 13.86 & 10.92 & 13.16 & 13.72 & 11.2 & 13.44 & 13.72 & 8.96 & 11.62 & 13.44 \\
\hline GUARAPIRANGA & 4 & 19 & 15.96 & 18.43 & 18.81 & 14.82 & 17.86 & 18.62 & 15.2 & 18.24 & 18.62 & 12.16 & 15.77 & 18.24 \\
\hline PIRAJUSSARA & 11 & 25 & 21 & 24.25 & 24.75 & 19.5 & 23.5 & 24.5 & 20 & 24 & 24.5 & 16 & 20.75 & 24 \\
\hline CONTRIB LATERAL TIETE & 24 & 28 & 23.52 & 27.16 & 27.72 & 21.84 & 26.32 & 27.44 & 22.4 & 26.88 & 27.44 & 17.92 & 23.24 & 26.88 \\
\hline
\end{tabular}

Table 3 Vulnerability categories.

\begin{tabular}{ll}
\hline Landslides occurrences & Vulnerability \\
\hline 1 & Short vulnerability \\
$2 \sim 6$ & Medium vulnerability \\
$6 \sim 12$ & High vulnerability \\
$>12$ & Very high vulnerability \\
\hline
\end{tabular}

Table 4 Landslides occurrences and distance of the IS (informal settlements).

\begin{tabular}{lllllll}
\hline River basin & ID basin (*Fig. 1) & Occurences & $100 \mathrm{~m}$ from IS & $100 \mathrm{~m}$ from IS & $300 \mathrm{~m}$ from IS & $300 \mathrm{~m}$ from IS \\
\hline Billings & 3 & 8 & 5 & $63 \%$ & 7 & $88 \%$ \\
Guarapiranga & 4 & 19 & 16 & $84 \%$ & 18 & $95 \%$ \\
Tamanduate Medio & 5 & 7 & 4 & $57 \%$ & 7 & $100 \%$ \\
Pirajussara & 11 & 25 & 18 & $72 \%$ & 23 & $92 \%$ \\
Aricanduva & 12 & 10 & 5 & $50 \%$ & 6 & $60 \%$ \\
Cabucu Medio & 22 & 7 & 4 & $57 \%$ & 7 & $100 \%$ \\
Contribuição Lateral Tiete & 24 & 28 & 12 & $43 \%$ & 20 & $71 \%$ \\
Ribeirão dos Meninos & 38 & 1 & 0 & $0 \%$ & 1 & $100 \%$ \\
Aguas Espraiadas & 41 & 9 & 7 & $78 \%$ & 9 & $100 \%$ \\
Cabucu de Baixo & 45 & 14 & 7 & $50 \%$ & 9 & $64 \%$ \\
Baixo Cabucu & 66 & 14 & 1 & $7 \%$ & 8 & $57 \%$ \\
Tamanduatei Inferior & 74 & 5 & 1 & $20 \%$ & 3 & $60 \%$ \\
Vertente Esquerda do Tiete & 77 & 14 & 6 & $43 \%$ & 12 & $86 \%$
\end{tabular}

*ID basin is related to each name and number in Fig. 1. 
Maps of landslides vulnerability can now be constructed considering the vulnerability functions and return period, in order to display spatial susceptibility to flooding along main regions in the city.

Fig. 4 shows vulnerability maps for $6,12,24$ and $48 \mathrm{~h}$ and return period from 2 to 10 years, and Fig. 3 shows the function that generate these maps. It is interesting to verify that very high vulnerability is present in even for high frequency events (2-yr return period), which denotes the danger of irregular occupations on those sub catchments. Considering landslides occurrences in a spatial visualization over houses/slums areas, it is possible to verify the correlations between those data.

Important information can be obtained by crossing the landslides location points, informal settlements mapped by Municipality of Sao Paulo and land slope, as shown in Figs. 5, 6 and Table 4. As commented

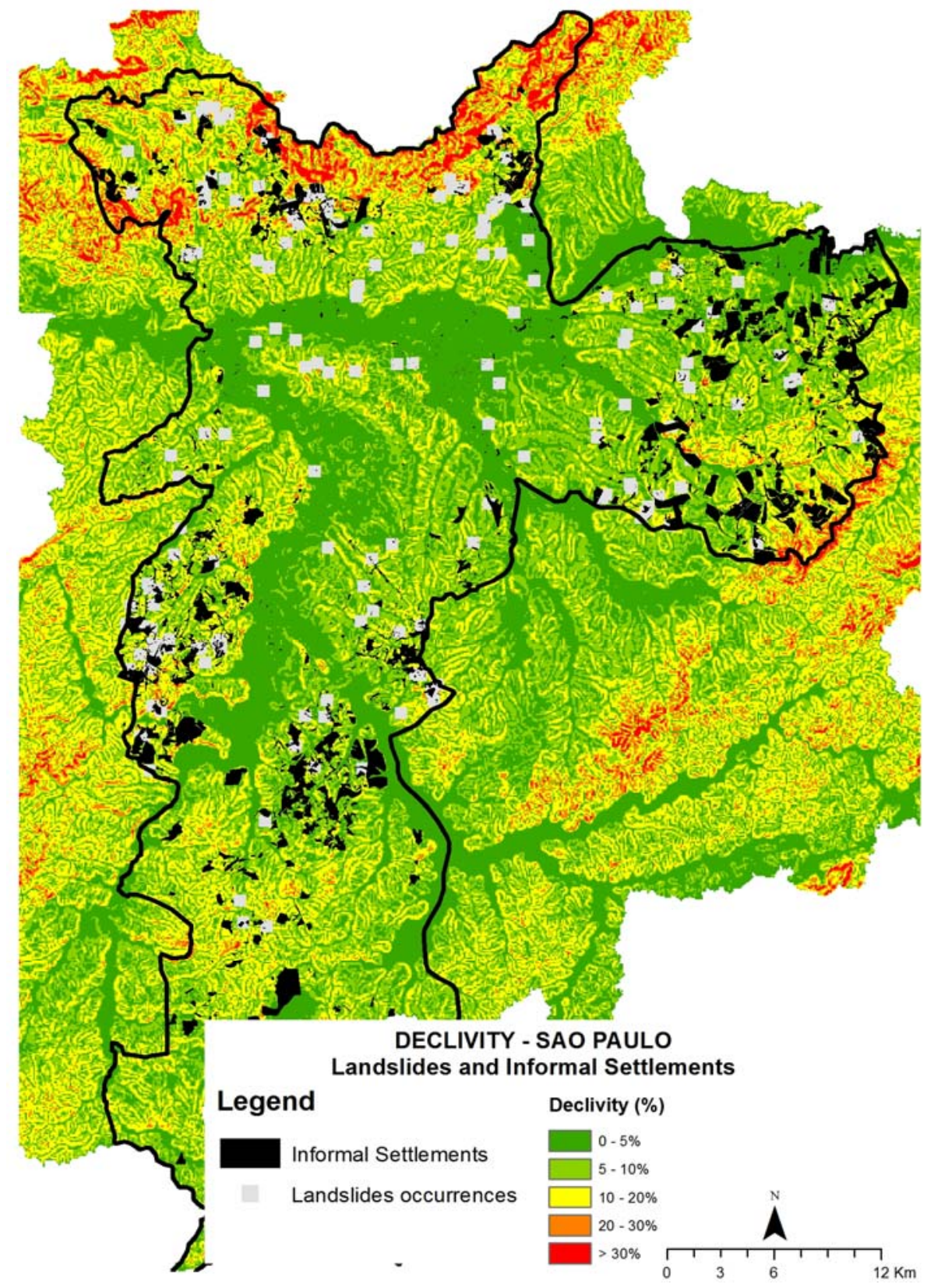

Fig. 6 Declivity map. 
before, informal settlements are mostly located in high slope areas as well river floodplains.

\section{Conclusions}

Occupation of sensible areas like top of hills, high slopes or river floodplains by low income people in large urban centers is frequently found around the world and is not different in Sao Paulo, sometimes with casualties related to rain events. Mapping landslides occurrences close to informal settlements is important in order to plan reurbanization and reallocation.

As a result, $48 \%$ of landslides occurrences where registered in a $100 \mathrm{~m}$ of the polygon around the informal settlements and $82 \%$ inside a $300 \mathrm{~m}$ polygon.

The use of the latest technology to accurately map rain distribution, land characteristics and occupation through GIS techniques and spatial and statistical analysis makes possible the correlation between the event magnitude and the number of occurrences.

The index of vulnerability functions presented in this study and the vulnerability maps for different river basins show that it is possible to build an efficient tool for emergency action plans formulation and public policies of risk reduction.

\section{References}

[1] IBGE. 2012. Data Download. IBGE. Accessed August 1, 2012. http://www.ibge.gov.br. (in Portuguese)

[2] DAEE. 2012. Reports of the Macro Drainage Master Plan for High Tiete Catchment. Sao Paulo: PDMAT 3. (in Portuguese)

[3] FCTH. 2013. Sao Paulo Area Flood Alert System (SAISP). São Paulo: FCTH. (in Portuguese)

[4] Son, K. R., Earl, F., and Andrioli, C. P. 2013. "Correction in Real Time of the Rainfall Estimated by a Meteorological Radar and a Network of Surface.” Presented at XX Brazilian Symposium on Water Resources, Bento Goncalves, Brazil, Nov., 2013. (in Portuguese)

[5] Martinez Jr., F., and Magni, N. L. G. 1999. Rainfall Equations for the State of São Paulo. Sao Paulo: DAEE. (in Portuguese)

[6] Perez, L. P., and Martins, J. R. S. 2014. "Vulnerability to Flooding in the City of Sao Paulo." Presented at International Conference of Flood Management, Sao Paulo, 2014.

[7] Perez, L. P. 2013. "Urban Vulnerability Index for Flooding and Landslides related to Extreme Climate Events in São Paulo: A Method Purposed.” Doctoral dissertation, University of Sao Paulo. (in Portuguese)

[8] EMPLASA. 1974. Mapping of the Executive Planning Group of São Paulo (GEGRAM). EMPLASA. (in Portuguese)

[9] Habi-SP: HABISP. 2008. Mapping the Housing in the City of Sao Paulo. Municipality of São Paulo. 